\title{
Curriculum and Instruction Basics for the New Engineering Educator
}

\section{Prof. Michael Allen Hayden Ph.D., Indiana State University}

Dr. Hayden is a Professor in the Department of Applied Engineering and Technology Management. He has a PhD in Industrial Education and Technology from Iowa State University. He has been teaching over 30 years and is a former department chair. He has certifications in manufacturing engineering and quality. He mainly teaching courses related to quality, R\&D, and applied statistics.

\section{Dr. Randell W. Peters, Indiana State University}

Dr. Peters is a professor of automotive engineering technology and chairperson of the Department of Applied Engineering and Technology Management in the College of Technology. His PhD from Indiana State University is in Curriculum Instruction and Media Technology specializing in Industrial Technology. He has been teaching for more than 12 years and has more than 25 years of automotive and motorsports industry experience. He maintains certifications and licensure in the National Hot Rod Association and holds 22 current certifications in Automotive Service Excellence. His teaching is focused in the area of automotive engines and motorsports management. 


\section{Curriculum and Instruction Basics}

For the Engineering Technology Educator 


\section{Curriculum and Instruction Basics for the Engineering Technology Educator}

New engineering faculty members can be overwhelmed with transitioning from practitioner to teacher [1]. There is more to teaching than presenting what one knows, e.g., teaching also includes curriculum development, evaluating student learning, and advising [2]. There is more to being a faculty member than teaching, scholarship and service are also required. The new faculty member must learn about and engage in accreditation, outcomes assessment, community engagement and many other professional and institutional concerns [3]. Even with the benefit of a possessing a PhD in higher education, no one can perfectly accomplish every faculty expectation. Even senior faculty members work at continuous improvement of their technical and teaching abilities and must triage their time and talents. There are basic insights and tips that can help a new faculty member make a good start and travel a smoother road. This paper will summarize some of those basics with the aim of helping the new faculty member efficiently and successfully transition to their new role. The paper will focus on the interrelated areas of what content to teach, how to teach the content, and how to integrate the teaching domain with other faculty member roles.

\section{What to Teach}

The following strategies for determining content are all better than randomly selecting content but can fall short of meeting program outcomes [4].

- $\quad$ Teach what you were taught.

- $\quad$ Go through the book, e.g., a chapter a week.

- $\quad$ Go through a list of topics, e.g., a topic a week.

Ideally, course content is determined by planning the program's curriculum so that the content of each course plays its part in achieving the program's educational objectives [5], [6], [7]. This is unlikely to translate to any of the above bullets. Neither academic freedom nor faculty purview implies that the faculty member can teach whatever they want to [8], [9]. See Figure 1. In a wellfunctioning department, e.g., fully accredited with complete ABET approved syllabi, the new faculty member should be able to focus on interpreting the bases of each pyramid in Figures 1 and 2. In an imperfect scenario, e.g., the faculty member is teaching a new course with existing syllabus, he or she can fall back on the bullets above.

Program educational objectives and program student outcomes are commonly developed by input from and/or the benchmarking of the following [10].

- Accreditation, industry, and professional standards

- $\quad$ Alums

- $\quad$ Programs at other institutions

- $\quad$ Practitioners

- $\quad$ The direct supervisors, customers, and co-workers of practitioners

- $\quad$ Executives of the companies which employ graduates

- Advisory committees composed of any of the above, but especially practitioners 
Figure 1. Faculty Curriculum Purview Hierarchy

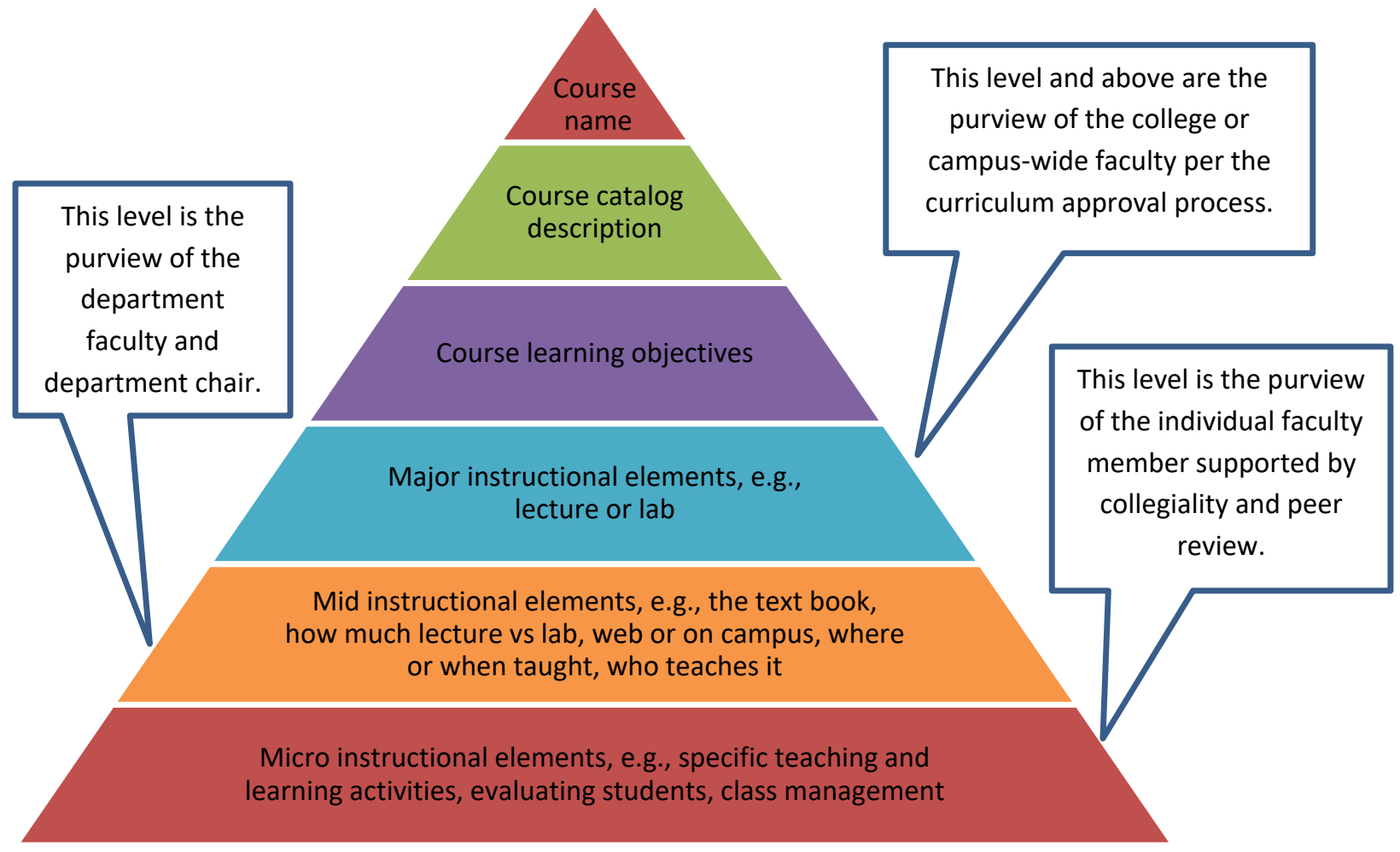


Figure 2. ABET Objectives Hierarchy

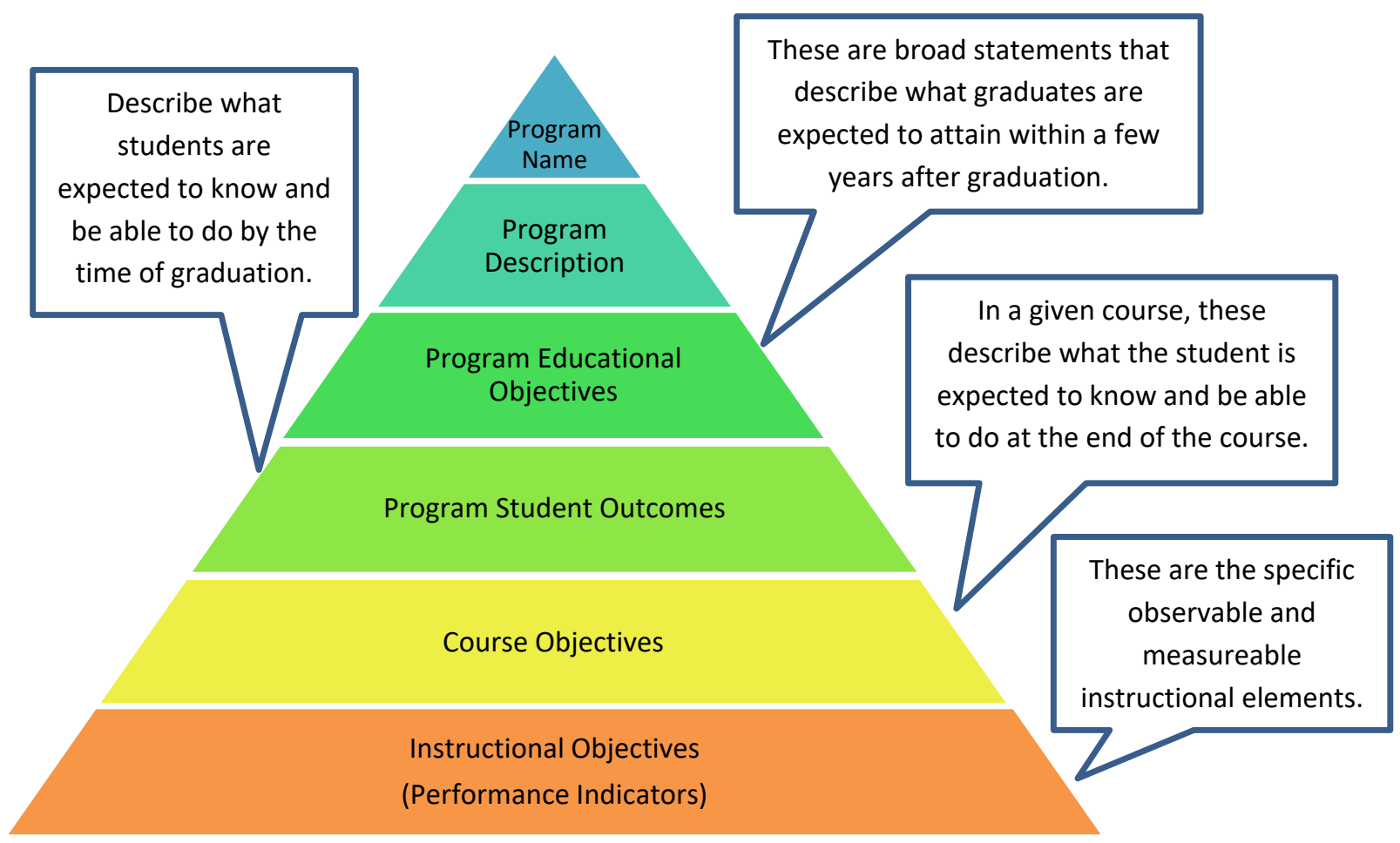

\section{Performance Indicators and Their Role in Instruction}

What ABET refers to as a performance indicator (PI) is called a behavioral, learning, or instructional objective in other fields [11].

The behavior. The core of a PI is the expected behavior or performance. This philosophy assumes that the student had to do something. For example the student had to demonstrate, create, write, or otherwise produce something. The thing could be a design, product, report, or artifact. The thing could be an action, e.g., operate a machine, use a tool, answer a question, or critique a production plan.

To be a behavior, action is required. Therefore, the behavior needs to be described with an action verb. Actions are observable and measureable. Verbs such as select, create and, explain are more easily defined and measured than understand, know, or experience.

The behavior portion of a PI should help achieve the program and course objectives. There is a wide selection of observable and measureable action verbs from which to select in stating performance. The factors in the following table are often used to determine and state a complete PI. 
Table 1. Performance Indicator Factors.

\begin{tabular}{|l|l|}
\hline \multicolumn{1}{|c|}{ Behavior Factors } & \multicolumn{1}{c|}{ Comments } \\
\hline Focus or intent & $\begin{array}{l}\text { What exactly is the desired behavior? To make a project plan for a } \\
\text { thing, to design the thing, to create the thing, to evaluate ... }\end{array}$ \\
\hline $\begin{array}{l}\text { Centrality or primacy } \\
\text { to the intent }\end{array}$ & $\begin{array}{l}\text { You might be primarily interested in the student } \text { creating a truss, but } \\
\text { in whole or part you have the student answer a multiple choice } \\
\text { question about trusses. Answering is an observable and measureable } \\
\text { action verb but it might be secondary (but as close as you can get) to } \\
\text { the primary behavior. }\end{array}$ \\
\hline Complexity & Memorization $\leftarrow \rightarrow$ Creating \\
\hline Difficulty & Easy $\leftarrow \rightarrow$ Hard \\
\hline $\begin{array}{l}\text { Level of mastery or } \\
\text { instructional step }\end{array}$ & Introduce $\leftarrow \rightarrow$ Master \\
\hline Specificity & Design a truss design $\leftarrow \rightarrow$ Design a wooden attic truss for a ... \\
\hline
\end{tabular}

Conditions. A complete PI states the conditions under which the behavior is demonstrated. Analogous to the behavior factors, there are many possible conditions such as time frame or duration, materials, tools or equipment, environmental conditions, information, and others.

Evaluation. A complete PI includes evaluation criteria. Remember, a good behavioral verb is observable and measureable. Is the observed thing a written test, an essay, a performance, a product, or something else? What is the instrument and/or procedure to collect the data, i.e., what is the test and/or instrument? The instrument could be your eye or the PE exam. Measurement is describing the test results in an interpretable manner. Are you going to measure by points on a test, score on a rubric, what? Evaluation is making a decision or judgment about the measurement or score. Does the student get an A or B? Did the student perform the behavior well enough or not? Ideally, the PI gives the teacher and student information about how the PI is evaluated and what it takes to pass or get a certain score for that PI.

\section{How to Teach}

How to teach what you intend to teach can be understood, organized, performed, and evaluated via PIs. In essence, teaching entails the following.

1. Providing (insuring, facilitating) the conditions under which the student will perform the behavior [12].

2. Guiding (modeling, coaching, enabling, allowing) the student to demonstrate the behavior [13], [14].

3. Testing, measuring, and evaluating the student's performance of the behavior [15].

There are many methods to accomplish the above. To accomplish the above also requires course management, advising, and other teaching and professorial activities. Some methods line up better with some topics than other topics. Teacher and learner attributes influence both content and methods [16]. 


\section{Teacher and Learner Attributes}

The following teacher and learner attributes are important to student achievement [17].

The instructor is an expert in the content. An instructor needs to have content knowledge several levels above the knowledge that students need to master [18]. New instructors can overwhelm their students by trying to teach the students all the instructor knows. The instructor should focus on the course's PIs. Note that as an instructor of a course you are probably not trying to turn students into miniature versions of yourself; you are teaching your part of the students' program. Also realize that students are dissimilar from you in significant ways, e.g., they probably will not have your aptitude and desire to be a $\mathrm{PhD}$ professor of the subject matter.

The instructor has control of the learning environment. This applies to course management, e.g., the instructor and the students staying on task and on schedule, Focusing on PIs is important to course management.

The student has the innate ability. Some believe that anyone can learn anything given enough time and the ideal conditions; true or not, programs and courses have practical constraints. Admissions criteria aim to best place students. Usually, the instructor has no direct role with placement, but the instructor can usually analyze individual or institutional data, e.g., SAT scores, to inform instructor decisions. Also, the instructor can administer pretests or engage the students in other activities to better understand student abilities.

The student has the prerequisite knowledge. Similar to above, review and pretests can be used to get students up to speed and oriented for the course. Prerequisites exist for a reason, i.e., to sequence objectives and PIs; they should be enforced.

The student has the will. By one theory, anyone can be motivated to do anything. By another theory, learning is up to the student. Those two theories are not necessarily mutually exclusive but as Yogi Berra said, "In theory, theory and practice are the same; in practice, they are not." In practice, the instructor will not have the time or talent to act as a life coach for every student. The instructor should be aware of student services provided by the campus and refer students to services as necessary. Students change programs to find a better fit for their talents and ambitions. As an instructor or advisor, it is beneficial for a student and for institutional effectiveness metrics for a student to be in a program for which he or she has the desire, aptitude, and preparation.

\section{Instruction Strategies}

Successful instructional strategies are related to structuring the learning environment so that the students can best achieve the PIs given the teacher and learner attributes [19], [20]. You can view instructional design, delivery, and evaluation as a project management task: there (a) are goals to be achieved, (b) are criteria and constraints, e.g., teacher and learner attributes, equipment, time, and other resources, and (c) should be a plan [21]. Given the inputs and the desired outcomes, there may be several possible plans. If there is no plan, it is unlikely that success can be 
documented or communicated even if the objectives are achieved. Outcomes assessment plans are usually tied to accreditation; PIs are key to both.

There are principles that apply to almost every instructional situation. The following list contains principles and strategies that are pertinent to most learning environments.

- The instruction should be challenging, yet obtainable. Students rise to the occasion; do not underestimate them but do not overwhelm them. Learning is best done in small steps; mastering one step before moving to the next [22].

- The average person takes 5 to 8 practices, with feedback, before they master something. Not all practices or exposures are equal. Students learn and retain the least by mere lecture and the most by the student demonstrating while explaining.

- The instructor is equal parts coach and judge; do both jobs fairly and consistently.

- Provide detailed instructions, the evaluation criteria, and graded examples of past work.

- Assess prerequisite knowledge and ability (preparation for the course), e.g., pretest and review. Adhere to course prerequisites and sequencing, e.g., degree maps.

- The instructor and students should stay on task and on schedule.

\section{Fairness}

What is most fair and most appropriate is for the PIs, the instruction, and the evaluation to flow in a chain as depicted in Figure 3.

Figure 3. Instructional Flow

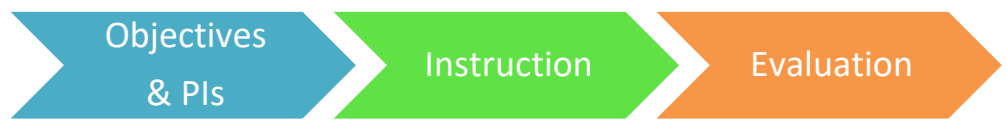

Note that the linkage is directional in delivering the instruction but might be reversed for curriculum and instructional development. If a program goal is to pass the PE exam, we would prudently look at the PE exam to decide what some PIs must be [5], [23]. In teaching a course, it is the instructor's duty to match instruction to the PIs and then evaluate the performance. The reader might think, shouldn't the evaluation match the instruction? The evaluation will match the instruction when the instruction matches the objectives.

What is most fair to the profession, the student, and the instructor is that the instruction is focused on the PIs, and the evaluation pertains to the achievement of the objectives. Consider Figures 4 and 5. 
Figure 4. Fair all the way around.

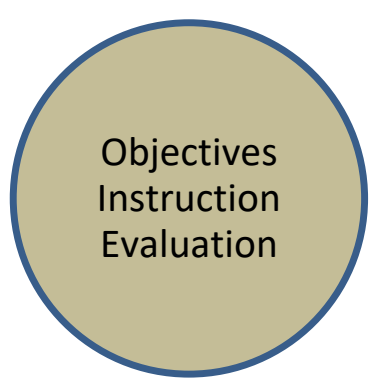

Figure 5. Unfair all the way around.

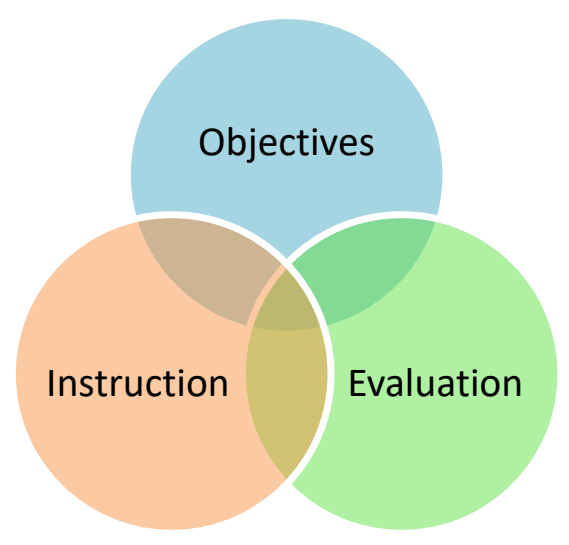

To summarize, teaching and learning are improved when a course is built around appropriate course objectives and PIs, especially if they are stated and understood by the instructor and the students [24]. When PIs are taught and accomplished, student success is improved, course management is improved, career readiness is improved, and career advancement is accelerated. ABET accreditation and most outcomes assessment plans require PIs.

\section{How to Survive and Thrive}

This section is included to provide advice on how to do well in the teaching, scholarship, and service domains and successfully work toward tenure and promotion with the least anxiety. Some basic quality, efficiency, and management techniques can improve your performance in all domains, while improving your work and home life.

Even if you get a position teaching at your alma mater, you will be a professor and not a student [25]. You will be in a new role; programs and professions evolve. Not all your activities and views as a student will or should translate to your new position [26]. When in Rome do as the Romans do; adapt to your institution, senior colleagues, and students [27]. There may be a good 
reason that the old timers are doing things a certain way and do not want to change. Avoid political battles. Be a helpful resource. Do your share but don't try to change the establishment until you are tenured. If you do not have enough to do, work on your teaching, write grants, and publish.

Practice what you teach [28]. Use your engineering and technical management abilities, e.g., plan your activities using value stream maps or activity network diagrams, employ cost-benefit analysis and Pareto charts to prioritize your activities, and apply Lean Six Sigma tools. Try not to do things that are not your responsibility or for which you do not have the authority [29].

Simplify your teaching, e.g., use three or four evaluation categories in a course, e.g., homework, exams, and a project. Use a grading scheme based on points and all points have equal value. Even for face-to-face courses, use course management software, e.g., BlackBoard, to record grades, to administer tests, and to submit homework. Software tools, e.g., Turnitin, can check for academic honesty; built in rubrics and comment functions that can speed evaluation and improve consistency of evaluation [30].

Don't reinvent the wheel. Partner with senior faculty members and seek their mentorship. Copy the best practices of others. Boilerplate and standardize everything you can [31].

Interact with students as more than a teacher or advisor. Treat students as junior colleagues, encouraging them to be active in student and senior chapters of professional organizations. Encourage students to treat school like a full-time professional job, dressing and acting accordingly.

The best thing you can do for yourself, your students, and the institution is to align and integrate the faculty domains of teaching, scholarship, and service. Ideally, a faculty member's degrees, work experience, professional memberships, and licenses are aligned with all three domains. The faculty member should embed mission-based activities, e.g., community engagement, into the three domains.

\section{Summary}

Rome was not built in a day. Be patient and pace yourself. Develop a plan. A logical starting point is to focus on teaching and evaluating PIs. Learn and apply basic teaching and learning strategies (but not all at once).Waste and lack of direction are the new faculty member's nemeses. Try to get the most bang for your buck by integrating your prior knowledge and experiences, continued professional development, teaching, scholarship, service, and all other activities. By practicing what you teach, you can efficiently accomplish the teaching, scholarship, and service goals necessary for promotion and tenure and have a fruitful and enjoyable career. 


\section{Reference List}

[1] R. Brent, R. Felder, S. Rajala, J. Gilligan and G. Lee, "New faculty 101: an orientation to the profession [engineering teacher training]," 31st Annual Frontiers in Education Conference. Impact on Engineering and Science Education. Conference Proceedings (Cat. No.01CH37193), Reno, NV, 2001, pp. S3B-1-3 vol.3. doi: 10.1109/FIE.2001.964046 [Accessed Jan. 11, 2018].

[2] C. Lucas, J. Murry, “Teaching: Lectures and Discussion," in New Faculty. New York: Palgrave Macmillan, 2011, pp. 39-63.

[3] J. Pedersen, G. Kunz, M. Kostelnik, and B. Doll, "A model for mentoring new faculty members," in Mentoring, and Work-Life (Im)Balance: Educators (Re)Negotiate the Personal, Professional, and Political, K. Mansfield, A. Welton, P. Lee., Eds. Charlotte, NC: Information Age Publishing, 2016, pp 239-252.

[4] R. Norton, "Determining What to Teach," International Vocational Education and Training Association (IVETA) Conference, 2000, Hong Kong. Retrieved from

http://repository.vtc.edu.hk/ive-adm-others-iveta/2000/standards/33 [Accessed Jan. 11, 2018].

[5] O. Boev, N. Gruenwald, and G. Heitmann, Eds. Engineering Curriculum Design Aligned with Accreditation Standards. Wismar, Germany: Hochschule Wismar, 2013.

[6] ABET, "Continuous improvement: The heart of accreditation.” [Online]. Available: ABET, http://www.abet.org/accreditation/get-accredited-2/continuous-improvement-the-heart-ofaccreditation/. Accessed Jan. 26, 2018.

[7] ABET, "Criteria for accrediting engineering technology programs, 2018 - 2019." [Online]. Available: ABET, http://www.abet.org/accreditation/accreditation-criteria/criteria-foraccrediting-engineering-technology-programs-2018-2019/. Accessed Jan. 26, 2018.

[8] AAUP, “1940 Statement of principles on academic freedom and tenure.” [Online]. Available: https://www.aaup.org/report/1940-statement-principles-academic-freedom-and-tenure. Accessed Jan. 26, 2018.

[9] A. Whitehead, "The Aims of Education," in The Aims of Education and Other Essays. New York, NY: The Free Press, 1929, pp 1-14.

[10] J. Passow, and C. Passow, "What Competencies Should Undergraduate Engineering Programs Emphasize? A Systematic Review," Journal of Engineering Education, 106: 475-526, 2017. doi:10.1002/jee.20171. [Accessed Jan. 11, 2018].

[11] R. Tyler, Basic Principles of Curriculum and Instruction. Reprint, Chicago: University of Chicago Press, 2013.

[12] J. Kemp, G. Morrison, and S. Ross, Designing Effective Instruction, $2^{\text {nd }}$ Ed. Upper Saddle River, NJ: Merrill, 1998. 
[13] T. Moore, S. Guzey, G. Roehrig, M. Stohlmann, M. Park, Y. Kim, H. Callender, and H. Teo, "Changes in Faculty Members' Instructional Beliefs while Implementing Model-Eliciting Activities," Journal of Engineering Education, 104: 279-302, 2015. doi:10.1002/jee.20081. [Accessed Jan. 11, 2018].

[14] S. Daly, E. Mosyjowski, and C. Seifert, "Teaching Creativity in Engineering Courses," Journal of Engineering Education, 103: 417-449, 2014. doi:10.1002/jee.20048. [Accessed Jan. $11,2018]$.

[15] M. Huba and J. Freed, Learner-Centered Assessment on College Campuses: Shifting the Focus from Teaching to Learning. Boston, MA: Allyn and Bacon, 2000.

[16] C. Conley, S. Ressler, T Lenox, and J. Samples, "Teaching Teachers to Teach Engineering- $\mathrm{T}^{4} \mathrm{E}$," Journal of Engineering Education, 89: 31-38, Jan 2000. doi:10.1002/j.2168-9830.2000.tb00491.x [Accessed Jan. 11, 2018].

[17] J. Stronge, P. Tucker and J. Hindman, Handbook for Qualities of Effective Teachers. Alexandria, VA: ASCD, 2004.

[18] W. Houston, Ed., Handbook of Research on Teacher Education. New York, NY: Macmillan, 1990.

[19] S. Atwood and J. Pretz, "Creativity as a Factor in Persistence and Academic Achievement of Engineering Undergraduates," Journal of Engineering Education, 105: 540-559, 2016. doi: 10.1002/jee.20130. [Accessed Jan. 11, 2018].

[20] M. DeMonbrun, C. Finelli, M. Prince, M. Borrego, P. Shekhar, C. Henderson, and C. Waters, "Creating an Instrument to Measure Student Response to Instructional Practices," Journal of Engineering Education, 106: 273-298, 2017. doi:10.1002/jee.20162. [Accessed Jan. $11,2018]$.

[21] L. Hickman and M. Akdere, "Stakeholder Theory: Implications for Total Quality Management in Higher Education," in Fourth International Conference on Lean Six Sigma for Higher Education, West Lafayette, IN, May 25-26, 2017, C. Laux, J. Antony, E. Cudney, Eds. [Online]. Available: https://docs.lib.purdue.edu/iclss/2017/. [Accessed Dec. 10, 2017].

[22] N. McNeill, E. Douglas, M., Koro-Ljungberg, D. Therriault, J. and I. Krause, "Undergraduate Students' Beliefs about Engineering Problem Solving," Journal of Engineering Education, 105: 560-584, 2016. doi:10.1002/jee.20150. [Accessed Jan. 11, 2018].

[23] R. Felder and R. Brent, "Designing and Teaching Courses to Satisfy the ABET Engineering Criteria," Journal of Engineering Education, 92: 7-25, Jan. 2003. doi:10.1002/j.21689830.2003.tb00734.x [Online]. [Accessed Jan. 11, 2018]. 
[24] M. Henri, M. Johnson, and B. Nepal, "A Review of Competency-Based Learning: Tools, Assessments, and Recommendations," Journal of Engineering Education, 106: 607-638, 2017. doi:10.1002/jee.20180. [Accessed Jan. 11, 2018].

[25] C. Bell, "How Work Role Transition Influences Professional Identity: The Career Path from Corporate Manager to University Professor," Ph.D. dissertation, The Graduate School of Education and Human Development, George Washington University, Washington, DC, 2015.[Online]. Available:

https://search.proquest.com/openview/e792b26baf42c4564e30f6d236dc0f7b/1?pqorigsite $=$ gscholar \&cbl $=18750 \&$ diss $=y$. [Accessed Jan. 8, 2018].

[26] E. Mosyjowski, A., S. Daly, D. Peters, S. Skerlos, and A. Baker, "Engineering PhD Returners and Direct-Pathway Students: Comparing Expectancy, Value, and Cost," Journal of Engineering Education, 106: 639-676, 2017. doi:10.1002/jee.20182. [Accessed Jan. 11, 2018].

[27] M. Besterfield-Sacre, M. Cox, M. Borrego, K. Beddoes, and J. Zhu, "Changing Engineering Education: Views of U.S. Faculty, Chairs, and Deans," Journal of Engineering Education, 103: 193-219, 2014. doi:10.1002/jee.20043. [Accessed Jan. 11, 2018].

[28] C. Finelli, S. Daly, and K. Richardson, "Bridging the Research-to-Practice Gap: Designing an Institutional Change Plan Using Local Evidence," Journal of Engineering Education, 103: 331-361, 2014. doi:10.1002/jee.20042. [Accessed Jan. 11, 2018].

[29] J. Lu, C. Laux, and A. Suresh, "Designing for Standardizing on Six Sigma Education," in Fourth International Conference on Lean Six Sigma for Higher Education, West Lafayette, IN, May 25-26, 2017, C. Laux, J. Antony, E. Cudney, Eds. [Online]. Available: https://docs.lib.purdue.edu/iclss/2017/. [Accessed Dec. 10, 2017].

[30] R. Felder, R. Brent, and M. Prince, "Engineering Instructional Development: Programs, Best Practices, and Recommendations," Journal of Engineering Education, 100: 89-122, 2011. doi:10.1002/j.2168-9830.2011.tb00005.x. [Accessed Jan. 11, 2018].

[31] M. Hayden and R. Peters, "The Elimination of Waste in Higher Education: Prescriptions for Doing the Right Things the Right Way," in Fourth International Conference on Lean Six Sigma for Higher Education, West Lafayette, IN, May 25-26, 2017, C. Laux, J. Antony, E. Cudney, Eds. [Online]. Available: https://docs.lib.purdue.edu/iclss/2017/. [Accessed Dec. 10, 2017]. 